\title{
Inequality of Rights of Senior Executives, Expected Performance Feedback and Management Efficiency
}

\section{Dakai Wang}

Nanjing Normal University, Nanjing City, Jiangsu, 210046, China

\begin{abstract}
As China's manufacturing industry is advancing the upgrading of its industrial structure, this paper discusses the influence of power imbalance in the top management team on enterprises' management efficiency, and also discusses, on such a basis, the contextual effect of expected performance feedback and joint contextual effect of expected performance feedback and product market competition in combination with the organizational behavior theory and principal-agent theory.
\end{abstract}

Keywords: Power Imbalance in Top Management Team; Expected Performance Feedback; Management Efficiency

DOI: http : //dx.doi.org/10.26549/jetm.v2i1.670

\section{Introduction}

U nder the grand context of the post-economic era, China's "world factory" advantages have faded away and the increasing factor cost has put the "outshining" position of China's manufacturing industry to a complete end. To cope with this, China proposed "The 12th Five-Year" Plan and "The 13th Five-Year" Plan and raised and stressed China's upgrading of its industrial structure to transform from "Made in China" to "Created in China". Under such a circumstance, China's manufacturing enterprises are bound to bear heavy burden. As a result, decreased cost and improved corporate management efficiency become important means to improve enterprises' competitiveness. ${ }^{[1]}$

So far, most studies of the academic circle on management efficiency mainly focus internal and external factors. The internal factors mainly includes nature of property right, business costs, investment in human capital, debt structure, allocation of factor capital, etc. ${ }^{[2,3,4,5,6]}$, while external factors mainly include degree of internationalization, market position of enterprises, labor market and product market competition degree, etc. ${ }^{[7,8,9]}$.

Researches have shown that the top management team plays a significant role in making enterprises' business decisions and improving enterprises' performance. ${ }^{[10]}$ The power of members of the top management team determines resources possessed by them and the power difference of them is reflected as power imbalance of the top management team. Therefore, we can believe that power imbalance of the top management team influences resource distribution and as a result influences the decision-making direction, decision-making efficiency of the top management team and enterprise performance. This is also an opinion held by some experts in the strategic management field, such as Smith. ${ }^{[1]}$ In addition, though some scholars argue that power imbalance of top management team can benefit organizations in China, study on this is still less so far. Therefore, the author integrates the 
organizational behavior theory, principal-agent theory and other theories to discuss how the power imbalance of top management team influences on management efficiency in China. As China is featured with great power distance, Chinese people hold a sense of collectiveness but have poor sensitivity for class gaps. Thus, we believe that in China, power imbalance of top management team is expected to contribute to increased management efficiency.

\section{Theoretical Analysis and Research Hypothesis}

\subsection{Power Imbalance and Management Efficiency of Top Management Team}

What is management efficiency? Management efficiency refers to the ratio between the input and output of an enterprise in management and can act as a basis to measure the enterprise's operation performance. Whereas, the top management team, as the important management of an enterprise, plays a decisive role for an enterprise's operating conditions. Thus, it can be deducted that the power distribution of the top management team can exert influence on the management efficiency. Given China has a high power distance and superior collectivism, team members can better accept the commands from their superior and thus make positive contributions to the team. Hence, the author of this paper believes that the power imbalance of top management team in China can produce positive influence on management efficiency. The specific influencing mechanism will work from the following three aspects.

First, the orientation of power distance and collectivism is an important measure to analyze the cultural background differences of different countries and regions. The difference in these two orientations will lead to great importance on the relationship between power and behavior. ${ }^{[12]}$ Numerous studies have shown that China is featured with high power distance and superior collectivism. ${ }^{[13]}$ On the one hand, in the high power distance-oriented culture, members of the top management team tend to have a stronger psychological sense of empowerment, pay greater attention to respecting and observing authority and tend to be easier to accept commands and suggestions from the superior. Under such a scenario, the inferior inclines to rely on their leaders' decisions and as a result the middle- and upper-level leaders of the team have the centralized decision-making power, which may even be favorable for the improvement of the inferior's work satisfaction. On the other hand, in high collectivism-oriented countries, team members become more interdependent in the process of finishing tasks and thus much more needs to be done for coordination and communication through power grades. Therefore, it can be inferred that hierarchy can play a more active role in China.
In addition, based on the theory of hierarchy, power and identity define an organization's hierarchy. Higher power and identity means that the higher an organization's hierarchy is, the higher the possession degree of valuable and scare resources of the organization will be and the higher the respect by others will be ${ }^{[14]}$ In general, an organization will grant higher hierarchy to its members who have made contributions, and vice versa. Therefore, in case of power imbalance in a top management team, the organization's hierarchy will encourage some individuals to behave in a manner beneficial to the team's success and improving the management efficiency.

On the contrary, power balance in the top management team will make executives with the balanced power contend for resources and positions in the organization, which tends to lead to destructive conflicts. ${ }^{[15]}$ and is bad for information sharing and teamwork. Identity balance is also prone to making executives' query on each other's decisions, thus lengthening the decision-making process and unfavorable for the improvement of enterprises' management efficiency.

Therefore, based on the above analysis, assumption 1 below is raised in this paper: In China, power imbalance of top management team is favorable for enterprises' management efficiency.

\subsection{Situational Functions of Expected Performance} Feedback Effect

Based on the organizational behavior theory, enterprise management will set a control point, i.e. expected performance to measure and judge the current performance. That is, they will employ the gap between the current performance and the expected performance to make the follow-up operating decisions and behavior patterns.

Expected performance refers to the minimum enterprise performance satisfactory to the senior management calculated based on the enterprise' historical performance and industry performance. Expected performance higher than the actual performance will throw an enterprise to a disadvantageous position. In such a condition, the senior management with concentrated power is likely to get out of the "dilemma" by finding means to improve the enterprise's performance, such as improving the management efficiency.

First, according to the organizational behavior theory, an actual performance lower than the expected performance indicates the necessity for an organization or enterprise to improve the current situation ${ }^{[16]}$ and that its senior management will definitely take measures to improve the management efficiency, thus propelling its development. Second, when an enterprise's actual performance is poorer than the expected performance, the enterprise will be con- 
fronted with greater pressure from the capital market and increased operation risks. As a consequence, the management's competence and reputation will be thrown to tremendous challenges. In order to avert "reputation" losses, the management will take the initiative to seek the causes and solutions against the problems. ${ }^{[16]}$ In this regard, the senior management with different powers in the top management team will make clear their own work roles and responsibilities, finished sound interactive, improve management efficiency and actively explore the channels and methods to cope with the problems under the leadership of the management with higher power. In addition, performance deficit will motivate the enterprise's owners to strengthen supervision on their agents in an attempt to weaken the agents' opportunist behaviors. In confrontation with such a circumstance, leaders in the management team with centralized power more accord with the assumption of the management theory, ${ }^{[17]}$ for they will improve the management efficiency in an attempt to raise the enterprise's performance. In the end, when the enterprise's actual performance is lower than the expected performance, the expected deficit will break the senior management's arrogance and self-confidence and stimulate them to acquire much more information concerning the enterprise's operation. ${ }^{[18]}$ In order to maintain internal harmony of the top management team and avoid conflicts among the senior management of the team, other members tend to obey their suggestions. Learning of enterprises' competitors' operation modes is favorable for the improvement of management efficiency.

On the contrary, based on the principal-agent theory, enterprises' management will have the "self-benefitting" motive. ${ }^{[19]}$ For the purpose of preventing the management to seek personal interest and damage the major shareholders' interest by making use of the rights granted by the Board of Directors, enterprises' owners will continue to supervise the management's management behaviors after the management acquires the enterprise right of management. When an enterprise's actual performance is higher than the expected performance, the enterprise has sound performance when the major shareholders decreases the supervision on the management and the management relaxes "vigilance". At this moment, if the power of the top management team is in an imbalanced status, for the sake of maintaining the team's harmony, other management members may sustain the above status, which will dampen the enterprise's management efficiency.

Based on the above analysis, assumption 2 is raised in this paper:

Assumptions 2: if the actual performance is poorer than the expected performance, the positive influence of the top management team's power imbalance will be intensified on the management efficiency and vice versa.

\section{Conclusions}

The manufacturing industry has exerted a crucial role for China's rapid economic development in the past 20-odd years, making China the "world factory". However, since the financial crisis in 2008, western countries raised the "reindustrialization strategy", posing tremendous challenges for China's manufacturing industry. To cope with this, China must upgrade its industrial structure, improve enterprise efficiency and develop competitive edges of enterprises.

The above discussion can provide certain enlightenment for China's enterprise development and policy making: (1) To improve enterprises' management efficiency, enterprises are suggested to establish reasonable power hierarchy, provide promotion goals for the management with lower power and decrease destructive conflicts and improve management efficiency of the team. (2) This paper holds that if the actual performance is poorer than the expected performance, the positive influence of the top management team's power imbalance will be intensified on the management efficiency and vice versa. Therefore, enterprises should set up reasonable hierarchy and choose senior management who has made contributions to the enterprise and can lead the enterprise to revitalize even the enterprises' performance is poor.

\section{References}

[1] Wei Cai, Yuxin Yu. Analysis on Factors Influencing Management Efficiency of China's Manufacturing Enterprises[J]. Shanghai Economic Review, 2012, (12): 87-94. (in Chinese)

[2] Xiaoxuan Liu, Liying Li. Efficiency Analysis on Corporate Property Right Reform[J]. Social Sciences in China Press, 2005,4 (2): 4-16. (in Chinese)

[3] Shuli Zhang, Yede Huang. Evaluation Methodology on Management Efficiency and Development of State-owned Enterprises[J]. Scientific Management Research, 2001, (8): 51-54. (in Chinese)

[4] Jiqiang Guo. Structural Analysis on Investment in Human Capital[J]. Economic Journal, 2005, (4): 689-706. (in Chinese)

[5] Hui Wang. Debt Financing, Corporate Governance and Market Value of Listed Companies[J]. Economic Research Journal, 2003, (8): 28-35.

[6] Li Chang, Angang Hu. Study on Factor Content of Manufacturing Trade of China, $[\mathrm{J}]$. Finance \& Trade Economics, 2011, (1): 86-93. (in Chinese)

[7] Gomes,L., and K.Ramaswa. An Empirical Examination of the Form of the Relationship between Multinationalityand Performance[J].Journal of International Business Studies, 1999,30 (1), 173-187. 
[8] Chongen Bai, Zhenjie Qian, Kangping Wu. Study on Determinants of Factor Allocation Shares of China's Industry Sector[J]. Economic Research Journal, 2008, (8): 16-28. (in Chinese)

[9] Jian Li, Beibei Yang, Zhen Pan. Product Market Competition, Management Shareholding and Management Efficiency-Study Based on Panel Data of China's Manufacturing Enterprises[J]. Journal of Guangdong University of Business Studies, 2016, (5): 72-83. (in Chinese)

[10] Qian,C., Cao,Q., Takeuchi,R.Top Management Team Functional Diversity and Organizational Innovation in China: TheModerating Effects of Environment[J]. Strategic ManagementJournal, 2013, 34(1): 110-120.

[11] Smith,A., Houghton,S.M., Hood,J.N., Ryman,J.A.PowerRelationships among Top Managers: Does Top ManagementTeam Power Distribution Matter for Organizational Performance?[J] Journal of Business Research, 2006, 59(5): 622-629.

[12] Zhong,C.B., Magee,J.C., Maddux,W.W., \& Galinsky,A.D. Power, Culture and Action: Considerations in the Expression and Enactment of Power in East Asian and Western Societies[J]. Research on Managing Groups and Teams, 2006,(9):53-73.

[13] Hofstede,G. Cultural Dimensions in Management and Plan-
ning[J].Asia Pacific Journal of Management,1984,1(2):81-99.

[14] Magee,J.C., Galinsky,A.D.Social Hierarchy:The Self-Reinforcing Nature of Power and Status[J].The Academy of Management Annals, 2008, 2(1): 351-398.

[15] Xuhua Wei, Yongmei Liu, Liuqing Yue. Influence of Power Imbalance in Top Management Team on Enterprises' Innovation Intensity-Mediated Mediation Effect[J]. Nankai Business Review, 2015,18 (3): 24-33. (in Chinese)

[16] Greve,H.R. Sticky Aspirations: Organizational Time Perspective and Competitivenes[J].Organization Science, 2002, 13 (1) : 1-17.

[17] Ting Xiong, Bo Cheng, Fei Pan. CEO Power, Product Market Competition and Corporate R\&D Investment[J]. Journal of Shanxi University of Finance and Economics, 2016, 38 (5): 56-68. (in Chinese)

[18] Yanling Lian, Xiaogang He, Hao Gao. Performance Expectation Gap and Corporate Strategy Adjustment*-empirical Study Based on China's Listed Companies[J]. Management World 2014, (11): 119-132. (in Chinese)

[19] Jian Li, DanShao, Zhen Pan. Influence of General Manager's Succession on Innovation Sustainability--Also on Regulatory Effect of Product Market Competition and Expected Performance Feedback Effect[J]. Science \& Technology Progress and Policy, 2017, 34 (10) 131-138. (in Chinese) 